\title{
СОСТОЯНИЕ СПЕРМАТОГЕНЕЗА И АНТИОКСИДАНТНОЙ АКТИВНОСТИ ЭЯКУЛЯТА У МОЛОДЫХ БЕСПЛОДНЫХ МУЖЧИН С ПОСТПУБЕРТАТНЫМ ВИСЦЕРАЛЬНЫМ ОЖИРЕНИЕМ И НЕОТЯГОЩЕННЫМ АНДРОЛОГИЧЕСКИМ АНАМНЕЗОМ
}

\author{
Бобков Д.Н., Роживанов Р.В. \\ ФГБУ «НМИЦ эндокринологии» Минздрава России, Москва
}

ЦЕЛЬ: оценка состояния сперматогенеза и антиоксидантной активности эякулята у пациентов с бесплодием, постпубертатным висцеральным ожирением и не отягощенным андрологическим анамнезом.

МАТЕРИАЛЫ И МЕТОДЫ: в сплошное одномоментное исследование было включено 100 бесплодных мужчин с постпубертатным алиментарным висцеральным ожирением в возрасте до 30 лет и 30 здоровых мужчин. Пациенты были разделены на две подгруппы: 58 мужчин с длиной окружности талии (OT) 98-101 см, и 42 мужчины с ОТ 102 см и более. Проводилась оценка уровня гонадотропинов и общего тестостерона, антиоксидантной активности (АОА) эякулята, его электронно-микроскопическое исследование. Статистически значимыми считали различия между группами при $\mathrm{p}<0,05$.

PЕзУЛЬТАТЫ: показатели сперматогенеза бесплодных мужчин с висцеральным ожирением были статистически значимо хуже таковых у здоровых мужчин: количество сперматозоидов в 1 мл эякулята у здоровых мужчин 87 [48;113] млн, у мужчин с ОТ 98-101 см 65,5 [31;96] млн и у мужчин с ОТ более 102 см 32 [15;45] млн; подвижность сперматозоидов a+b 67 [55;77]\%, 60 [48;67]\% и 51,5 [25;61]\% соответственно, сперматозоидов с дефектами головки $79[75 ; 83] \%, 83[79 ; 86] \%$ и 87 [85;89]\% соответственно (для всех сравнений в подгруппах $\mathrm{p}<0,05)$. АОА эякулята при висцеральном ожирении была ниже, чем у здоровых мужчин - у здоровых 2,4 [1,5;2,8] мМ-экв, у мужчин с ОТ 98-101 см 1,9 [1,0;2,2] мМ-экв и у мужчин с ОТ 102 см и более - 1,0 [0,9;1,2] мМ-экв, р<0,001. Кроме того, для больных с ожирением были характерны более низкие показатели уровня тестостерона: у здоровых 18,5 [16;27,5] нмоль/л, у мужчин с ОТ 98-101 см 14,1 [12,9;16,3] нмоль/л и у мужчин с ОТ 102 см и более - 11,9 [9,9;16,2] нмоль/л, p<0,01.

Выводы: у молодых бесплодных мужчин с постпубертатным висцеральным ожирением и не отягощенным андрологическим анамнезом показатели сперматогенеза хуже наблюдаемых у здоровых мужчин. При небольшой выраженности висцерального ожирения (ОТ менее 102 см) количественные показатели сперматогенеза в большинстве случаев соответствуют нормальным значениям, однако АОА эякулята уже является патологической, что свидетельствует о развитии оксидативного стресса даже при не выраженном висцеральном ожирении. 